\title{
Characterizing the spatial and temporal variation of malaria incidence in Bangladesh, 2007
}

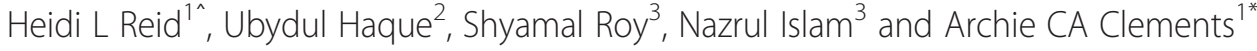

\begin{abstract}
Background: Malaria remains a significant health problem in Bangladesh affecting 13 of 64 districts. The risk of malaria is variable across the endemic areas and throughout the year. A better understanding of the spatial and temporal patterns in malaria risk and the determinants driving the variation are crucial for the appropriate targeting of interventions under the National Malaria Control and Prevention Programme.

Methods: Numbers of Plasmodium falciparum and Plasmodium vivax malaria cases reported by month in 2007, across the 70 endemic thanas (sub-districts) in Bangladesh, were assembled from health centre surveillance reports. Bayesian Poisson regression models of incidence were constructed, with fixed effects for monthly rainfall, maximum temperature and elevation, and random effects for thanas, with a conditional autoregressive prior spatial structure.

Results: The annual incidence of reported cases was 34.0 and 9.6 cases/10,000 population for $P$. falciparum and P. vivax respectively and the population of the 70 malaria-endemic thanas was approximately 13.5 million in 2007. Incidence of reported cases for both types of malaria was highest in the mountainous south-east of the country (the Chittagong Hill Tracts). Models revealed statistically significant positive associations between the incidence of reported $P$. vivax and $P$. falciparum cases and rainfall and maximum temperature.

Conclusions: The risk of $P$. falciparum and P. vivax was spatially variable across the endemic thanas of Bangladesh and also highly seasonal, suggesting that interventions should be targeted and timed according to the risk profile of the endemic areas. Rainfall, temperature and elevation are major factors driving the spatiotemporal patterns of malaria in Bangladesh.
\end{abstract}

Keywords: Malaria, Bangladesh, Spatial, Temporal, Seasonality, Bayesian, Plasmodium falciparum, Plasmodium vivax

\section{Background}

Spatial and temporal variability in malaria transmission are known to be driven partly by ecological factors that affect the survival and population size of anopheline vectors. Temperature, humidity and water available for breeding habitats have been shown to be important primary ecological factors [1]. Fluctuation in malaria risk has significant public health implications for ensuring adequate provision of anti-malarials, the delivery of intermittent preventative therapy (IPT) and optimizing the timing and frequency of indoor residual spraying with insecticides and/or distribution of long-lasting insecticidal nets (LLIN), and thus warrants investigation.

\footnotetext{
* Correspondence: a.clements@uq.edu.au

Deceased

'Infectious Disease Epidemiology Unit, Level 4 Public Health Building, School of Population Health, University of Queensland, Herston, QLD 4006, Australia Full list of author information is available at the end of the article
}

At a macro-scale, attempts have been made to understand the mechanisms driving malaria risk. The Mapping Malaria Risk in Africa (MARA) collaboration developed maps that describe the expected duration and timing of the transmission season by country based on climate suitability models $[2,3]$. Insight into the underlying ecological mechanisms both inhibiting and propelling malaria transmission has led to research into malaria early warning systems (MEWS) to be able to predict disease patterns based on known relationships between the disease and ecological variables [4-11].

A host of issues, however, make characterizing the natural phenomena underlying spatial and temporal patterns in malaria risk difficult. Differences in ecological requirements between malaria vectors mean that particular environmental events, such as the rainy season, can lead to an increase in vector capacity for most vectors but an initial

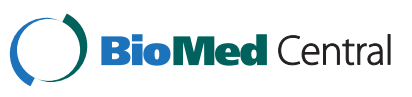


decrease for others [12-14]. Variability due to ecological drivers can be further complicated by patterns in host immunity, which is a possible explanation for intra-annual and inter-annual variation [15-17]. In addition, the longitudinal datasets required for analysis of both spatial and temporal patterns are commonly obtained from national health information system systems, from which the accuracy of estimates is highly variable [18].

The advancement of geographical information systems (GIS) and spatial statistics has greatly improved the understanding of malaria dynamics, including its dependence on ecological factors. Bayesian geostatistical models are now commonly employed to generate malaria risk maps providing a valuable evidence base for programmatic decision-making [19-26]. For malaria data aggregated by administrative area, as is often the case with health information system data, Bayesian conditional autoregressive (CAR) models have been used to model spatial and temporal patterns [17,27-29]. This approach has the advantage of accounting for spatial correlation in the data and smoothing out variability associated with small populations in some areas.

Malaria remains a significant health problem in Bangladesh affecting 13 of 64 districts. In 2006, the Global Fund to Fight AIDS, Tuberculosis, and Malaria awarded Bangladesh \$39.6 million US dollars to support the national malaria-control programme [30]. Three key objectives of the programme are to provide effective diagnosis and treatment to $80 \%$ of estimated malaria cases by 2012 , to promote the use of LLINs in $80 \%$ of households in these districts, and to use selective indoor residual spraying for containment of outbreaks [30].

While spatial patterns of Plasmodium falciparum prevalence have been previously described in Bangladesh [26], spatiotemporal patterns of $P$. falciparum and Plasmodium vivax incidence have not. The aims of this study were to describe the spatiotemporal patterns of reported malaria cases and identify environmental drivers of the spatiotemporal patterns of malaria risk in Bangladesh. This information may affect the timing and geographical targeting of interventions such as indoor residual spraying and distribution of LLINs. Through the more focussed implementation of interventions, the findings presented here have the potential to enhance the effectiveness of the national malaria control programme and provide valuable baseline epidemiological information upon which to chart the progress of the programme.

\section{Methods}

\section{Malaria surveillance data and descriptive methods}

The Bangladesh Ministry of Health lists malaria as a notifiable disease and maintains routine surveillance of clinical malaria nationwide. Cases of malaria diagnosed at health facilities are reported to the thana health complex, and collated up through the district and division administrative levels. From 2004 to 2009, cases in Bangladesh were confirmed as uncomplicated malaria presumptive (UMP), uncomplicated malaria confirmed (UMC), as well as severe malaria (SM) and vivax malaria (VM). Neither microscopy nor rapid diagnosis tests (RDT) were performed for UMP, but for the others, either microscopy or a RDT was used for diagnosis. According to official national figures, $98 \%$ of confirmed cases were diagnosed using microscopy in 2007 and $2 \%$ using a RDT, with approximately $76 \%$ of cases being UMP [31]. Since 2007, the situation has changed, with $63 \%$ of cases diagnosed using a RDT and only $10 \%$ of cases being UMP in 2010 [32].

For the purposes of the present study, reported numbers of $P$. vivax and $P$. falciparum malaria cases across all age groups were assembled by month for each of the 70 thanas in the 13 endemic districts between January and December 2007. Population data from the national census conducted in 2001 were adjusted according to national growth figures [33], assuming an even population growth across all thanas. The population was then used as a denominator to calculate malaria incidence in each thana. In the 13 malaria-endemic districts, the incidence of reported $P$. falciparum malaria cases for the whole of 2007 was compared to prevalence determined by population-based surveys using RDTs conducted in the same year [34]. Pairwise, Pearson cross correlations between incidence of $P$. falciparum and $P$. vivax for each month (January-December) were calculated to determine whether the distribution of the two species was related.

\section{Climate and elevation data}

A number of ecological and climatic factors affect both the extrinsic life cycle of the malaria parasite and that of the anopheline vectors [35]. Based on published literature, variables pertinent to malaria transmission in Bangladesh were selected for statistical analysis. High-resolution (1 sq km) raster maps of interpolated long-term average monthly rainfall, and minimum and maximum temperature, were obtained from the WORLDCLIM project [36]. Digital elevation data (in meters above sea level for cells of a $1 \mathrm{sq} \mathrm{km}$ grid), were obtained from the same source.

Data concerning vegetation cover were obtained from the GlobCover Land Cover product, which is derived from satellite imagery from 2005 to 2006 [37]. Vegetation was labelled according to the United Nations (UN) Land Cover Classification System [38] at a resolution of $300 \mathrm{~m}$. For this analysis, vegetation cover was dichotomized into forested, which included multiple specific forest categories, and not forested, which included all other vegetation categories.

Rainfall, temperature, elevation and vegetation maps were imported into the geographical information system (GIS) ArcView version 9 (ESRI, Redlands, CA, USA) and linked spatially to a digitized boundary map of the 70 malaria-endemic thanas. For each thana, the mean values 
of the raster cells contained in the thana for rainfall, temperature and elevation, and percentage forest cover, were computed in the GIS to define covariates in subsequent models. Environmental variables were standardized by centreing the covariates on their mean and dividing by the standard deviation to assist mixing and convergence of the spatiotemporal models.

\section{Statistical analysis}

Bayesian spatiotemporal Poisson regression models were constructed using the WinBUGS software, version 1.4.3 (MRC Biostatistics Unit, Cambridge, UK). The outcome was the monthly number of reported cases of $P$. vivax or $P$. falciparum malaria (January to December 2007) in each thana and the offset was the expected number of cases based on the population of each thana.

The final regression model was:

$$
O_{i j} \sim \operatorname{Poisson}\left(\mu_{i j}\right) \text {, }
$$

where $O_{i j}$ is the observed number of cases in thana $i$, month $j$ and

$$
\log \left(\mu_{i j}\right)=\log \left(E_{i}\right)+\theta_{i j}
$$

where $E_{i}$ is the expected monthly number of cases in thana $i$, which did not vary by month because the population was considered static. The mean log relative risk was modelled as:

$$
\theta_{i j}=\alpha+\beta \tilde{n} e l e v_{i}+\delta \tilde{n} \operatorname{prec}_{i j}+\phi \tilde{n} t e m p_{i j}+s_{i}
$$

where $\alpha$ is the intercept, $\beta, \delta$ and $\varnothing$ are the coefficients for mean elevation (elev), precipitation (prec), and maximum temperature (temp), respectively, and $s_{i}$ is a spatial countylevel random effect. Note, minimum temperature and percent forest cover were excluded because of collinearity (Pearson's correlation $>|0.7|$ ) with maximum temperature and elevation, respectively. Spatial structuring in $s_{i}$ was modelled using a conditional autoregressive prior structure, where spatial relationships between counties were modelled using a simple adjacency weights matrix [39]. If two counties were adjacent, the weight $=1$ and if they were not adjacent, the weight $=0$. Non-informative priors were used for the intercept (an unbounded uniform, or flat, prior), coefficients (Gaussian priors with mean $=0$ and variance $=$ $10,000)$ and the variance of $s_{i}$ (a gamma prior with shape and scale parameters $=0.01$ ). Models were created with, and without, the environmental covariates to determine their ability to capture spatial and temporal effects in the data. The residuals of the models were examined to determine whether any temporal patterns, including seasonality and temporal autocorrelation, remained after adjusting for the effects of rainfall and temperature. Additionally, models were compared using the deviance information criterion (DIC) to determine whether incorporation of the environmental covariates improved the fit of the models (a lower DIC indicates a better-fitting model).

\section{Results}

The population of the 70 malaria-endemic thanas was approximately 13.5 million in 2007 . In these thanas, there was a total of 45,761 reported cases of $P$. falciparum malaria in 2007, representing a crude incidence of 34.0 cases per 10,000 people; and 12,968 reported cases of $P$. vivax malaria, representing a crude incidence of 9.6 cases per 10,000 people. Maps revealed high reported incidence of both species in the south-east of the country (i.e. the Chittagong Hill Tracts) (Figure 1).

The monthly incidence of reported $P$. vivax and $P$. falciparum cases is shown by thana in Figure 2 . It is evident that in some thanas there was a strong seasonal pattern but that incidence was highly over-dispersed. Seasonal comparisons between the two types of malaria are clearer on a plot of the overall incidence for the 13 endemic districts (Figure 3). P. falciparum showed a peak in incidence in July while $P$. vivax peaked in June. There was a moderately high correlation (range $0.30-0.62$ ) between incidence of reported $P$. falciparum and $P$. vivax in any given month (Table 1). At the district level, there was also a strong positive association between the incidence of reported cases of $P$. falciparum malaria and the prevalence of $P$. falciparum infection determined by the population-based surveys conducted in the same year (Figure 4).

The $P$. falciparum and $P$. vivax models revealed similar positive associations with maximum temperature and monthly precipitation (Tables 2 and 3). The impact of elevation on the risk of $P$. falciparum and $P$. vivax differed, with a higher risk of $P$. falciparum and a lower risk of $P$. vivax at increasing elevation.

Residual analysis indicated that incorporation of environmental variables was effective in removing seasonality from the data, with only a small amount of unstructured temporal variation and no temporal autocorrelation evident in the residuals (indicating that it was not necessary to incorporate a temporal autoregressive term in the model). The environmental covariates were also able to explain some of the spatial variability in malaria counts, measured through the variance of the spatial random effect $\left(s_{i}\right)$. Inclusion of environmental variables into the models reduced the variance of the spatial random effect by $32.4 \%$ for $P$. falciparum and $6.7 \%$ for $P$. vivax compared to models without environmental covariates (Table 2). Incorporation of the environmental models improved the fit of the models for both types of malaria, as indicated by a lower DIC.

\section{Discussion}

Malaria in Bangladesh exhibits distinct spatial and temporal patterns, with varying levels of endemicity and significant, biologically tenable relationships to environmental variables. 


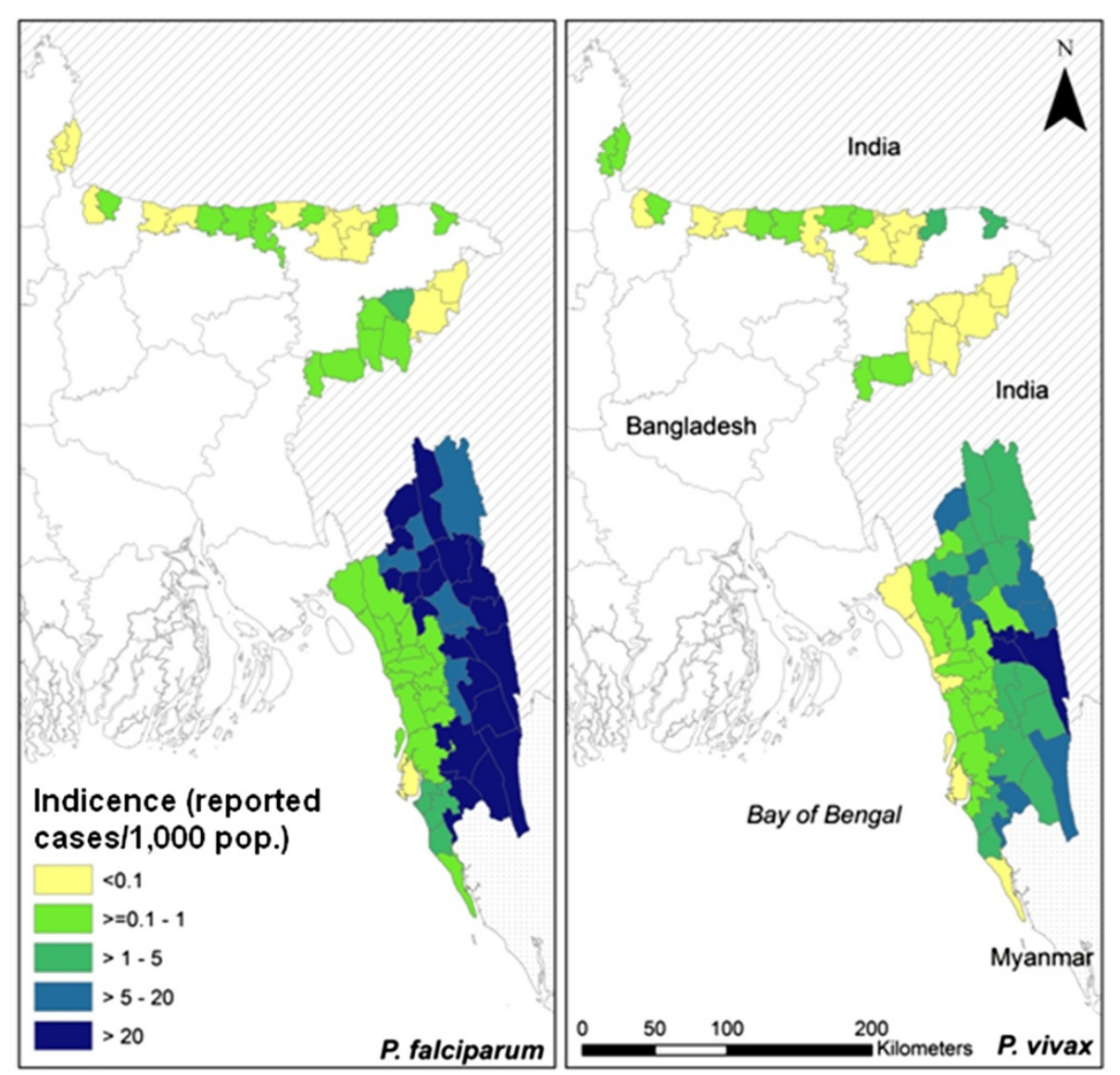

Figure 1 Incidence of reported cases of Plasmodium falciparum and Plasmodium vivax per 1,000 people across the endemic thanas in Bangladesh, 2007.
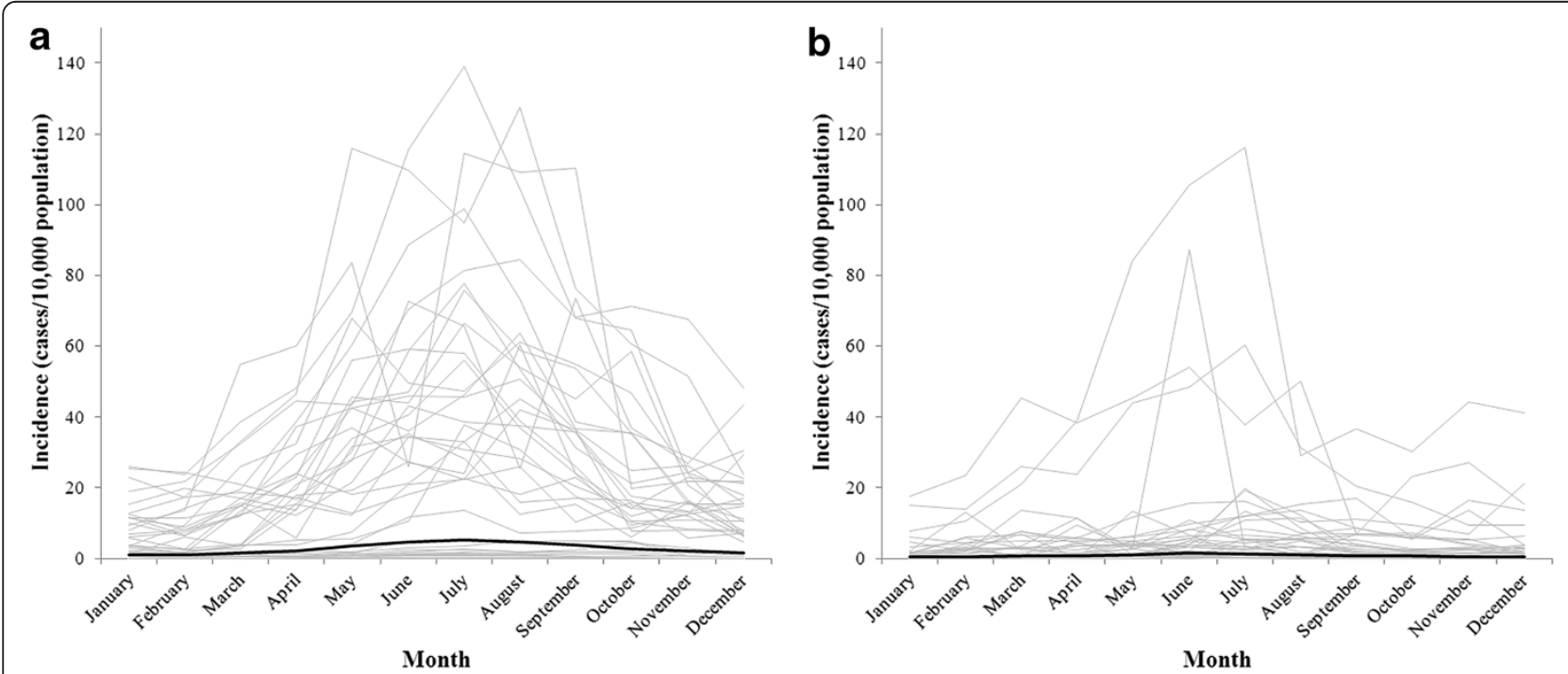

Figure 2 Thana-level monthly incidence (grey lines) and overall reported incidence across endemic thanas (black lines) of reported cases of A. Plasmodium falciparum and B. Plasmodium vivax malaria in Bangladesh, 2007. 


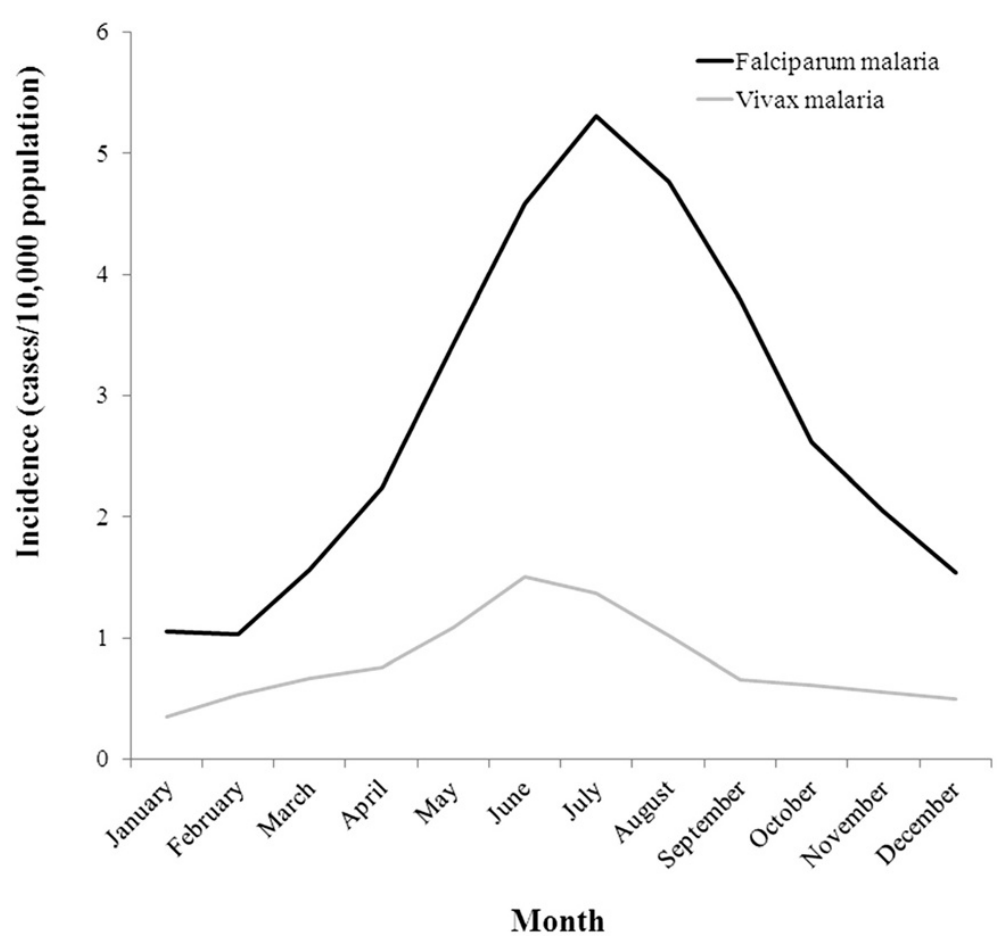

Figure 3 Monthly incidence of reported cases of Plasmodium falciparum and Plasmodium vivax across endemic thanas in Bangladesh, 2007.

Importantly, the analysis provides insight into the relatively unexplored epidemiology of $P$. vivax within the country.

The inclusion of ecological covariates in the model provided some explanation as to the temporal and spatial variation in malaria risk. Temperature and rainfall showed an expected positive relationship with increased malaria risk, which is consistent with similar analyses of incidence data

\section{Table 1 Pearson cross correlations comparing the thana- level incidence of Plasmodium vivax with Plasmodium falciparum for each month}

\begin{tabular}{ll}
\hline Month & $\begin{array}{l}\text { Correlation between the incidence of } \boldsymbol{P} \text {. falciparum and } \\
\text { P. vivax in each month }\end{array}$ \\
\hline January & P. falciparum/P. vivax \\
February & 0.52 \\
March & 0.52 \\
April & 0.36 \\
May & 0.45 \\
June & 0.30 \\
July & 0.38 \\
August & 0.62 \\
September & 0.50 \\
October & 0.39 \\
November & 0.39 \\
December & 0.55 \\
\hline
\end{tabular}

from Ethiopia, Peru and China [17,40,41]. These two variables were effective in explaining the seasonal patterns in the data. The environmental covariates could explain a sizable percentage of spatial variability observed in distribution of $P$. falciparum but only a relatively modest percentage seen with $P$. vivax. Other unmeasured factors including local malaria control activities [42], socio economic indicators [43] and population movement [44] are likely to contribute to variability in malaria risk, to differing degrees for the two species. The positive relationship between P. falciparum and elevation (after adjusting for the effects of temperature) could be explained by higher elevations providing denser forest cover and a more favourable environment for forest breeding vectors known to sustain transmission in these areas [45]. However, given that the vectors for the two species overlap in Bangladesh, the opposite finding for $P$. vivax was unexpected. With little known about the epidemiology of $P$. vivax in the country, this finding requires further investigation. However, of note, the odds ratio for elevation in the $P$. vivax model was of a small magnitude and was only marginally significant.

Plasmodium falciparum and P. vivax showed broadly similar spatial distributions which is consistent with more recent entomological information that suggests the same vectors are able to transmit both species. A study conducted in three ecologically distinct areas of the Chittagong Hill Tracts identified eight Anopheles species to be positive for circumsporozoite protein with a number of 


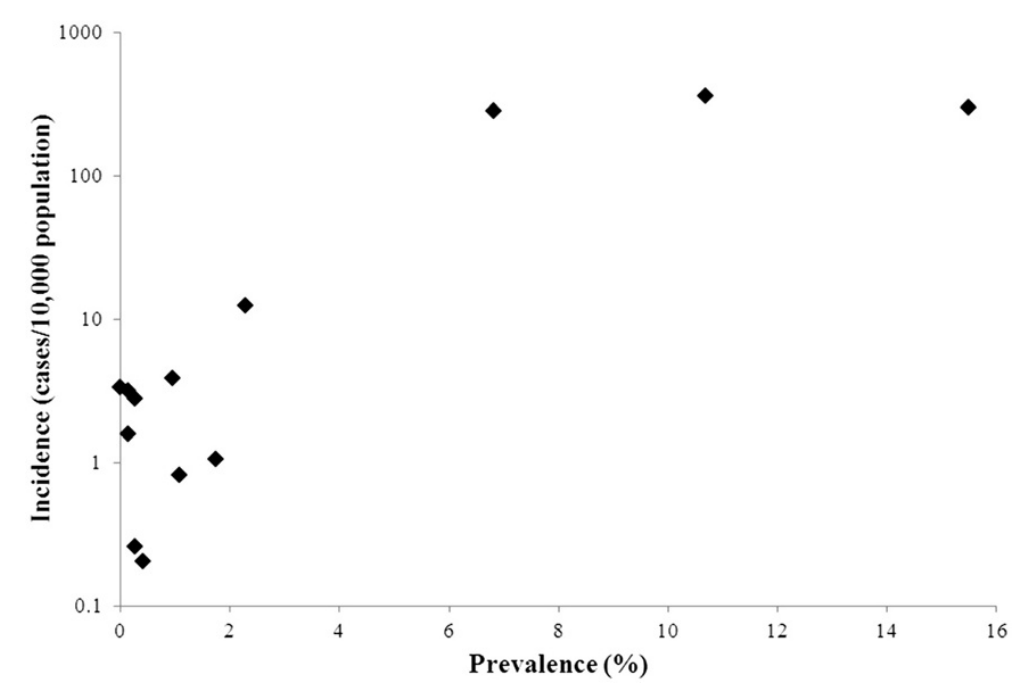

Figure 4 A comparison of incidence of reported cases of Plasmodium falciparum malaria by district and the prevalence of $P$. falciparum infection from population-based surveys using rapid diagnostic tests in the 13 malaria-endemic districts of Bangladesh, 2007.

these vectors infected by both P. falciparum and P. vivax [46]. Prior to this study no data were available documenting vectors of $P$. vivax in Bangladesh. The moderately high correlation between the incidence of P. falciparum and $P$. vivax for each of the months supports the entomological evidence, although this could be affected by factors such as geographical differences in the quality of laboratory practices that are used to differentiate malaria due to the different parasites. The correlation between $P$. falciparum and $P$. vivax, and the effect estimates in the P. vivax models, could also be sensitive to relapsing of vivax malaria. Unfortunately the surveillance system was not able to differentiate relapsing infections from primary $P$. vivax infections and it was not possible to test the potential impact of relapsing infections. Inter-species interactions, including cross-protective immunity, might influence observed heterogeneity of malaria infections in areas co-endemic for P. falciparum and P. vivax [47]. Additionally, background or ongoing malaria control could influence the ability to accurately quantify correlations between $P$. falciparum and $P$. vivax malaria and effect estimates (such as between elevation and malaria incidence) in the analysis.
The results presented here suggest that $P$. vivax is more widespread than found in cross-sectional surveys conducted in the same year [34]. Depending on the accuracy of diagnosis of $P$. vivax malaria in the surveillance system, this has significant implications for treatment of $P$. vivax, with national treatment guidelines recommending the use of chloroquine and primaquine [48]. Primaquine has been associated with acute haemolytic anaemia in patients with G6PD deficiency and, therefore, knowledge of the prevalence and geographical distribution of this inherited blood condition in $P$. vivax endemic areas is important [49]. The only cross-sectional data on G6PD deficiency in Bangladesh found a prevalence of $10.7 \%$ [50].

An important consideration for this analysis is that the data were obtained through the national passive surveillance system, which is known to grossly under-report malaria infections [34]. One contributing factor is that many infections are asymptomatic. Asymptomatic infections have been shown to be significant in Bangladesh, with two to 40 asymptomatic cases per 1,000 population reported in the Chittagong region [51]. Additionally, cases who seek treatment through private health services are not registered by

Table 2 Bayesian Poisson regression models of Plasmodium falciparum, Bangladesh, 2007

\begin{tabular}{llc}
\hline \multicolumn{1}{c}{ Variable } & \multicolumn{1}{c}{$\begin{array}{c}\text { With environmental } \\
\text { covariates }\end{array}$} & $\begin{array}{c}\text { Without environmental } \\
\text { covariates }\end{array}$ \\
\hline Intercept & $-1.23(-1.28--1.19)$ & $-1.02(-1.06--0.98)$ \\
Elevation $(10 \mathrm{~m}$ increase) & $1.45(1.39-1.49)$ & \\
Maximum temperature $\left(1^{\circ} \mathrm{C}\right.$ increase) & $1.012(1.011-1.013)$ & $0.15(0.10-0.21)$ \\
Precipitation (100 $\mathrm{mm}$ increase) & $1.15(1.14-1.15)$ & 23356.4 \\
Variance CAR random effect $\left(s_{i}\right)$ & $0.10(0.07-0.14)$ & 11774.6 \\
Deviance Information Criterion & & \\
\hline
\end{tabular}

*Estimates for the covariates are relative risks; results show mean and 95\% credible interval (Crl). 
Table 3 Bayesian Poisson regression models of Plasmodium vivax, Bangladesh, 2007

\begin{tabular}{|c|c|c|}
\hline Variable & $\begin{array}{c}\text { With environmental } \\
\text { covariates }\end{array}$ & $\begin{array}{c}\text { Without environmental } \\
\text { covariates }\end{array}$ \\
\hline Intercept & $-1.02(-1.14--0.92)$ & $-0.93(-1.05--0.84)$ \\
\hline Elevation (10 m increase) & $0.98(0.96-1.00)$ & \\
\hline Maximum temperature $\left(1^{\circ} \mathrm{C}\right.$ increase $)$ & $1.010(1.009-1.011)$ & \\
\hline Precipitation (100 mm increase) & $1.09(1.09-1.10)$ & \\
\hline Variance CAR random effect $\left(s_{i}\right)$ & $0.11(0.07-0.15)$ & $0.12(0.08-0.17)$ \\
\hline Deviance Information Criterion & 8950.1 & 10735.8 \\
\hline
\end{tabular}

the national surveillance system. Misdiagnosis and underreporting of malaria infections might affect the estimate of mean incidence, the proportion of cases that are $P$. vivax and the observed spatial patterns in the data, if there was systematic spatial variation in the quality of the surveillance system, as well as the effect estimates of the environmental covariates. Without being able to measure the quality of the surveillance system, it is not possible to speculate as to what the magnitude of these effects might be. However, the comparison of incidence reported through the national passive surveillance system, and prevalence determined by population-based survey methods, showed strong congruence at the district level (Figure 4). This is consistent with recent research that indicates incidence (calculated according to active case detection data) increases smoothly and then flattens out as prevalence increases [52], increasing confidence in the observed spatial patterns in the incidence data reported here. Seasonal migration of people, particularly workers, might also affect observed spatial patterns. Another limitation is the short time series (12 months) used in this analysis. A longer time series is needed to establish longer-term temporal variability of malaria, including important inter-annual patterns, seasonal patterns, and the predictive value of climatic risk factors.

Health information system data have been used to establish spatial variation of disease risk for $P$. falciparum and $P$. vivax in Bangladesh. Given the observed spatial and temporal variation, targeting of interventions has the potential to enhance the effectiveness of the national malaria-control programme in Bangladesh.

\section{Authors' contributions}

HLR, UH and ACAC conceived the study. HLR conducted the analysis and drafted the manuscript. UH compiled the data, assisted with the analysis and interpretation of the results, and contributed to the final draft. SR and NI facilitated access to the data and provided contextual information necessary to interpret the findings. ACAC provided guidance on the analysis and drafting of the manuscript. All authors read and approved the final manuscript.

\section{Acknowledgements}

ACAC is supported by a National Health and Medical Research Council Career Development Award. UH is supported by an A. Ralph and Sylvia E. Barr Fellowship from the Johns Hopkins Bloomberg School of Public Health W. Harry Feinstone Department of Molecular Microbiology and Immunology. This paper is dedicated to Heidi Reid in recognition of her brief but glittering contribution to malaria epidemiology and for the lasting impression she made on her colleagues and dear friends.

\section{Author details}

'Infectious Disease Epidemiology Unit, Level 4 Public Health Building, School of Population Health, University of Queensland, Herston, QLD 4006, Australia. ${ }^{2}$ Department of Molecular Microbiology and Immunology, Johns Hopkins Bloomberg School of Public Health, Baltimore, MD 21205, USA. ${ }^{3}$ Ministry of Health and Family Welfare, Malaria and Parasitic Disease Control, Director General of Health Services, Mohakhali, Dhaka, Bangladesh.

Received: 5 April 2012 Accepted: 10 May 2012

Published: 21 May 2012

\section{References}

1. Stresman GH: Beyond temperature and precipitation: ecological risk factors that modify malaria transmission. Acta Trop 2010, 116:167-172.

2. Craig MH, Snow RW, le Sueur D: A climate-based distribution model of malaria transmission in sub-Saharan Africa. Parasitol Today 1999, 15:105-111.

3. Tanser FC, Sharp B, le Sueur D: Potential effect of climate change on malaria transmission in Africa. Lancet 2003, 362:1792-1798.

4. Hay SI, Were EC, Renshaw M, Noor AM, Ochola SA, Olusanmi I, Alipui N, Snow RW: Forecasting, warning, and detection of malaria epidemics: a case study. Lancet 2003, 361:1705-1706.

5. Bouma MJ, van der Kaay HJ: The El Nino Southern Oscillation and the historic malaria epidemics on the Indian subcontinent and Sri Lanka: an early warning system for future epidemics? Trop Med Int Health 1996, 1:86-96.

6. Thomson MC, Connor SJ: The development of malaria early warning systems for Africa. Trends Parasitol 2001, 17:438-445.

7. Abeku TA, de Vlas SJ, Borsboom G, Teklehaimanot A, Kebede A, Olana D, van Oortmarssen GJ, Habbema JD: Forecasting malaria incidence from historical morbidity patterns in epidemic-prone areas of Ethiopia: a simple seasonal adjustment method performs best. Trop Med Int Health 2002, 7:851-857.

8. Rogers DJ, Randolph SE, Snow RW, Hay SI: Satellite imagery in the study and forecast of malaria. Nature 2002, 415:710-715.

9. Abeku TA, Hay SI, Ochola S, Langi P, Beard B, de Vlas SJ, Cox J: Malaria epidemic early warning and detection in African highlands. Trends Parasitol 2004, 20:400-405.

10. Ceccato P, Connor SJ, Jeanne I, Thomson MC: Application of geographical information systems and remote sensing technologies for assessing and monitoring malaria risk. Parassitologia 2005, 47:81-96.

11. Cox J, Abeku TA: Early warning systems for malaria in Africa: from blueprint to practice. Trends Parasitol 2007, 23:243-246.

12. Ratanatham S, Upatham ES, Prasittisuk C, Rojanasunan W, Theerasilp N, Tremongkol A, Viyanant V: Bionomics of Anopheles minimus and its role in malaria transmission in Thailand. Southeast Asian I Trop Med Public Health 1988, 19:283-289.

13. Rosenberg R, Andre RG, Somchit L: Highly efficient dry season transmission of malaria in Thailand. Trans R Soc Trop Med Hyg 1990, 84:22-28.

14. Somboon P, Aramrattana A, Lines J, Webber R: Entomological and epidemiological investigations of malaria transmission in relation to population movements in forest areas of north-west Thailand. Southeast Asian J Trop Med Public Health 1998, 29:3-9. 
15. Hay SI, Myers MF, Burke DS, Vaughn DW, Endy T, Ananda N, Shanks GD, Snow RW, Rogers DJ: Etiology of interepidemic periods of mosquitoborne disease. Proc Natl Acad Sci USA 2000, 97:9335-9339.

16. Hay SI, Rogers DJ, Shanks GD, Myers MF, Snow RW: Malaria early warning in Kenya. Trends Parasitol 2001, 17:95-99.

17. Clements AC, Barnett AG, Cheng ZW, Snow RW, Zhou HN: Space-time variation of malaria incidence in Yunnan province. China Malar J 2009, 8:180.

18. Guerra CA, Gikandi PW, Tatem AJ, Noor AM, Smith DL, Hay SI, Snow RW: The limits and intensity of Plasmodium falciparum transmission: implications for malaria control and elimination worldwide. PLOS Med 2008, 5:e38

19. Kleinschmidt I, Omumbo J, Briet O, van de Giesen N, Sogoba N, Mensah NK, Windmeijer $P$, Moussa M, Teuscher T: An empirical malaria distribution map for West Africa. Trop Med Int Health 2001, 6:779-786.

20. Gemperli A, Vounatsou P, Sogoba N, Smith T: Malaria mapping using transmission models: application to survey data from Mali. Am J Epidemiol 2006, 163:289-297.

21. Kazembe LN, Kleinschmidt I, Holtz TH, Sharp BL: Spatial analysis and mapping of malaria risk in Malawi using point-referenced prevalence of infection data. Int J Health Geogr 2006, 5:41

22. Noor AM, Clements AC, Gething PW, Moloney G, Borle M, Shewchuk T, Hay SI, Snow RW: Spatial prediction of Plasmodium falciparum prevalence in Somalia. Malar J 2008, 7:159.

23. Noor AM, Gething PW, Alegana VA, Patil AP, Hay SI, Muchiri E, Juma E, Snow RW: The risks of malaria infection in Kenya in 2009. BMC Infect Dis 2009, 9:180

24. Gosoniu L, Vounatsou P, Sogoba N, Maire N, Smith T: Mapping malaria risk in West Africa using a Bayesian non-parametric non-stationary model. Comput Stat Data Anal 2009, 53:3358-3371.

25. Reid H, Vallely A, Taleo G, Tatem AJ, Kelly G, Riley I, Harris I, Henri I, lamaher S, Clements AC: Baseline spatial distribution of malaria prior to an elimination programme in Vanuatu. Malar J 2010, 9:150.

26. Reid H, Haque U, Clements AC, Tatem AJ, Vallely A, Ahmed SM, Islam A, Haque R: Mapping malaria risk in Bangladesh using Bayesian geostatistical models. Am J Trop Med Hyg 2010, 83:861-867.

27. Kleinschmidt I, Sharp B, Mueller I, Vounatsou P: Rise in malaria incidence rates in South Africa: a small-area spatial analysis of variation in time trends. Am J Epidemiol 2002, 155:257-264.

28. Nobre AA, Schmidt AM, Lopes HF: Spatio-temporal models for mapping the incidence of malaria in Pará. Environmetrics 2005, 16:291-304.

29. Mabaso ML, Vounatsou P, Midzi S, Da Silva J, Smith T: Spatio-tempora analysis of the role of climate in inter-annual variation of malaria incidence in Zimbabwe. Int J Health Geogr 2006, 5:20.

30. Anon: Malaria situation in Bangladesh 2008. Malaria Situation in SEAR Countries: World Health Organization; 2009.

31. Anon: Monthly malaria diseases specific report. In. Dhaka. Bangladesh Directorate General of Health Services; 2007.

32. Anon G: Malaria disease specific report. Dhaka. Bangladesh: National Malaria Control Programme, Directorate General of Health Services; 2010.

33. Anon: World Population Prospects: The 2010 Revision, Volume 1: Comprehensive Tables. New York: United Nations Department of Economic and Social Affairs Population Division; 2010:2011.

34. Haque U, Ahmed SM, Hossain S, Huda M, Hossain A, Alam MS, Mondal D, Khan WA, Khalequzzaman M, Haque R: Malaria prevalence in endemic districts of Bangladesh. PLoS One 2009, 4:e6737

35. Molineaux L: The epidemiology of human malaria as an explanation of its distribution, including some implications for its control. In Malaria: Principles and Practice of Malariology. vol. 2nd edition. Edited by Wernsdorfer WH, McGregor I. London: Churchill Livingstone; 1988:913-998.

36. Hijmans RJ, Cameron SE, Parra JL, Jones PG, Garvis A: Very high resolution interpolated climate surfaces for global land areas. Int J Climatol 2005, 25:1965-1978

37. Bontemps S, Defourny P, Van Bogaert E: Globcover 2009 product description and validation report. Louvain: European Space Agency and Université Catholique de Louvain; 2010

38. Di Gregorio A, Jansen LJM: Land Cover Classification System (LCSS). Rome: Food and Agriculture Organization; 2000.

39. Besag J, York J, Mollié A: Bayesian image restoration, with two applications in spatial statistics. Ann Inst Stat Math 1991, 43:1-59.
40. Abeku TA, van Oortmarssen GJ, Borsboom G, de Vlas SJ, Habbema JD: Spatial and temporal variations of malaria epidemic risk in Ethiopia: factors involved and implications. Acta Trop 2003, 87:331-340

41. Chowell G, Munayco CV, Escalante AA, McKenzie FE: The spatial and temporal patterns of falciparum and vivax malaria in Peru: 1994-2006. Malar J 2009, 8:142.

42. Gething PW, Smith DL, Patil AP, Tatem AJ, Snow RW, Hay SI: Climate change and the global malaria recession. Nature 2010, 465:342-345.

43. Bui HM, Clements AC, Nguyen QT, Nguyen MH, Le XH, Hay SI, Tran TH, Wertheim HF, Snow RW, Horby P: Social and environmental determinants of malaria in space and time in Viet Nam. Int J Parasitol 2010, 41:109-116.

44. Childs DZ, Cattadori IM, Suwonkerd W, Prajakwong S, Boots M: Spatiotemporal patterns of malaria incidence in northern Thailand. Trans R Soc Trop Med Hyg 2006, 100:623-631.

45. Rosenberg R: Forest malaria in Bangladesh. III. Breeding habits of anopheles dirus. Am J Trop Med Hyg 1982, 31:192-201.

46. Alam MS, Khan MG, Chaudhury N, Deloer S, Nazib F, Bangali AM, Haque R: Prevalence of anopheline species and their Plasmodium infection status in epidemic-prone border areas of Bangladesh. Malar J 2010, 9:15.

47. Haghdoost AA, Alexander N: Systematic review and meta-analysis of the interaction between Plasmodium falciparum and Plasmodium vivax in humans. J Vector Borne Dis 2007, 44:33-43.

48. Anon: Revised malaria treatment regimen. In. Dhaka. Bangladesh: Directorate General of Health Services Ministry of Health and Family Welfare; 2009

49. Nkhoma ET, Poole C, Vannappagari V, Hall SA, Beutler E: The global prevalence of glucose-6-phosphate dehydrogenase deficiency: a systematic review and meta-analysis. Blood Cells Mol Dis 2009, 42:267-278.

50. Papiha SS, Roberts DF, Ali SG, Islam MM: Some hereditary blood factors of the Bengali Muslim of Bangladesh (red cell enzymes, haemoglobins, and serum proteins). Humangenetik 1975, 28:285-293.

51. Khan WA, Sack DA, Ahmed S, Prue CS, Alam MS, Haque R, Khyang J, Ram M, Akter J, Nyunt MM, Norris D, Glass G, Shields T, Haq MZ, Cravioto A, Sullivan DJ Jr: Mapping hypoendemic, seasonal malaria in rural Bandarban, Bangladesh: a prospective surveillance. Malar J 2011, 10:124.

52. Patil AP, Okiro EA, Gething PW, Guerra CA, Sharma SK, Snow RW, Hay SI: Defining the relationship between Plasmodium falciparum parasite rate and clinical disease: statistical models for disease burden estimation. Malar J 2009, 8:186.

doi:10.1186/1475-2875-11-170

Cite this article as: Reid et al:: Characterizing the spatial and temporal variation of malaria incidence in Bangladesh, 2007. Malaria Journal 2012 $11: 170$

\section{Submit your next manuscript to BioMed Central and take full advantage of:}

- Convenient online submission

- Thorough peer review

- No space constraints or color figure charges

- Immediate publication on acceptance

- Inclusion in PubMed, CAS, Scopus and Google Scholar

- Research which is freely available for redistribution 